\title{
A Rare Case of Tuberculous Pleural Effusion Diagnosed by Ziehl Neelson Stain
}

\section{Avinash Kumar* and Anshul Kumar}

Department of Microbiology, Tata Motors Hospital, Kharangajhar, Jamshedpur, India

${ }^{*}$ Corresponding author: Avinash Kumar, Specialist, Department of Microbiology, Tata Motors Hospital, Kharangajhar, Jamshedpur-831004, India, Tel: 9654876021; Email: lakchya@gmail.com

Received date: February 02, 2018; Accepted date: February 22, 2018; Published date: February 28, 2018

Copyright: (c) 2018 Kumar A, et al. This is an open-access article distributed under the terms of the Creative Commons Attribution License; which permits unrestricted use; distribution; and reproduction in any medium; provided the original author and source are credited.

\begin{abstract}
Mycobacterium tuberculosis is the etiologic agent of tuberculosis which remains the leading cause of mortality, internationally. It commonly affects the lungs but can also infect other parts of the body. Extra pulmonary tuberculosis (EPTB) includes lymphatic, pleural, skeletal, ocular, endometrial, pancreatic, genitourinary, cerebral, and meningeal or military tuberculosis. In India EPTB, particularly of Pleural cavity is reported rarely. Pleural effusion is an excessive accumulation of fluid in the pleural cavity which, in normal condition, contains a relatively small amount of fluid-approximately $10 \mathrm{ml}$ on each side. The idea of this article is to diagnose TB of pleural cavity by Ziehl Neelson staining, which usually presents with fever, weight loss and cough.
\end{abstract}

Keywords: Mycobacterium tuberculosis; Ziehl Neelson stain; Extra pulmonary tuberculosis; Tuberculous pleural effusion

\section{Introduction}

Tuberculosis $(\mathrm{TB})$ remains a leading public health problem across the world, with approx. 9 million new cases and 1.5 million TB deaths every year [1]. India stays to have the highest number of TB cases in the world, with over 2 million active TB cases which accounts for $25 \%$ of international TB burden every year [2]. Even though reliable data from India are lacking, $15-20 \%$ of all TB is extra pulmonary. Extra pulmonary tuberculosis (EPTB) is defined as occurrence of TB in parts of the body other than the lungs. Other types of EPTB are lymphatic, pleural, skeletal, central nervous system, pleural, ocular, endometrial, pancreatic, genitourinary, miliary and cerebral tuberculosis. The prevalence of EPTB is higher in HIV co infected patients and children [3].

Here, we report a case of Tuberculosis of pleural cavity diagnosed after one month of complain of respiratory symptoms. The patient had cough and weight loss for one month.

\section{Case Presentation}

A male patient of 26-years, non-diabetic, normotensive, native from Jharkhand, admitted with the complaints of cough and fever for 1 month with increased weight loss since 6 weeks. Patient was HIV negative (by ELISA) with no past history or exposure of tuberculosis infection. Patient also had no family history of tuberculosis, Diabetes, Hypertension.

Patient was conscious cooperative but ill looking. On examination patient was febrile, BP-110/70. His physical examination was suggestive of left pleural effusion. So the patient was investigated with chest X-ray which indicated significant flat air and left pleural effusion (Figure 1).

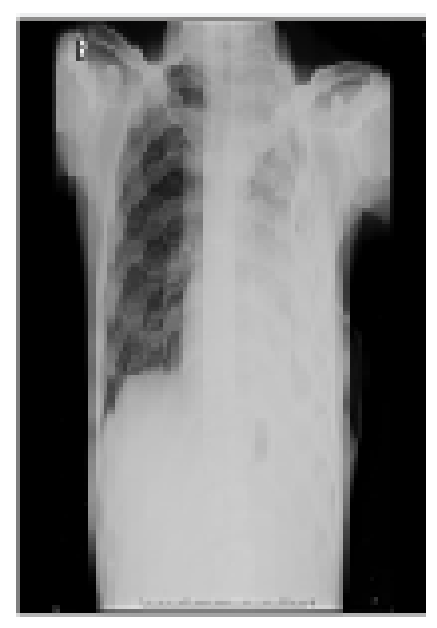

Figure 1: Chest x-ray (PA view) showing left sided pleural effusion.

Complete investigations with different parameters were done to diagnose the cause of Pleural effusion. All lab reports were within normal range except pleural Adenosine deaminase (188.6 U/l),Total count (12400), Serum uric acid (1.5), serum creatinine (0.5), serum alkaline phosphate (225U/1), LDH (18,2030 U/l (Table 1).

After all aseptic precaution, thoracocentesis was done on left side and $560 \mathrm{ml}$ of pus like fluid drained. The fluid was investigated for Microbiological, cytological and biochemical analysis (Table 2). Plenty of neutrophils with 8-10 AFB/100 Oil Immersion Field (OIF) were seen on Zeihl Neelson (ZN) stain of Pleural fluid (Figure 2).

$\mathrm{ZN}$ stain was done with one positive and one negative control as per universal guidelines. 
Page 2 of 2

\begin{tabular}{|l|l|l|l|}
\hline Parameters & Results & $\begin{array}{l}\text { Reference } \\
\text { Range }\end{array}$ & Indicator \\
\hline Haemoglobin & 10.4 & $13.3-16.2$ & Below Normal \\
\hline Total Count & 12400 & $4000-11000$ & Above Normal \\
\hline Neutrophil & 78 & $60-70$ & Above Normal \\
\hline Lymphocyte & 13 & $30-40$ & Below Normal \\
\hline Serum creatinine & 0.5 & $0.6-1.2$ & Below Normal \\
\hline Serum uric acid & 1.5 & $3.1-7$ & Below Normal \\
\hline $\begin{array}{l}\text { Serum } \\
\text { phosphoate Alkaline }\end{array}$ & 225 & $40-129$ & Above Normal \\
\hline Sodium & 126 & $13-146$ & Below Normal \\
\hline Potassium & 3.2 & $3.5-5$ & Below Normal \\
\hline $\begin{array}{l}\text { Serum } \\
\text { HBsAg/HCV ELISA }\end{array}$ & Negative & & \\
\hline ESR & $22 m m$ in 1st hour & & Above normal. \\
\hline $\begin{array}{l}\text { Sputum Microscopy } \\
\text { for AFB }\end{array}$ & No AFB seen & & \\
\hline $\begin{array}{l}\text { Pleural fluid for ZN } \\
\text { stain }\end{array}$ & $8-10$ AFB/100 OIF & & \\
\hline ZN-Ziehl Neelson; ESR-Erythrocyte Sedimentation Rate. & \\
\hline
\end{tabular}

Table 1: Parameters and results of case.

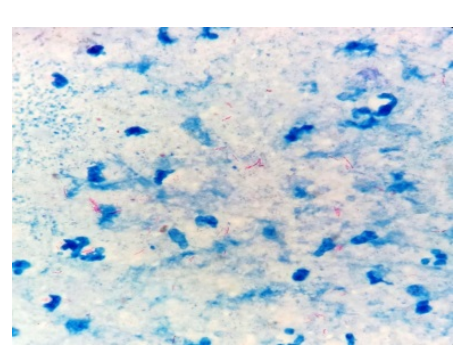

Figure 2: Ziehl Neelson stain: AFB as pink rods.

\begin{tabular}{|l|l|l|}
\hline Microbiology & Cytology & Biochemistry \\
\hline $\begin{array}{l}\text { Gram stain: Plenty of polymorphs } \\
\text { with no microorganism seen. }\end{array}$ & $\begin{array}{l}\text { Total Count-850 } \\
\text { Cells }\end{array}$ & Protein-4.1gm/dl \\
\hline ZN stain:8-10 AFB/100 OIF* seen & $\begin{array}{l}\text { Differential Count } \\
\text { Polymorph-80\% } \\
\text { Lymphocytes-20\% }\end{array}$ & LDH-18,2030U/l \\
\hline Bacterial culture-Sterile & & ADA-188.6U/l \\
\hline
\end{tabular}

Table 2: Pleural fluid investigations.

\section{Discussion}

Pleural effusion is second most common extra pulmonary tuberculosis next to tuberculosis lymphadenitis. About $20 \%$ cases of extra pulmonary tuberculosis presented with pleural effusion [4].

Most literatures supports that, MTB is the most common cause $(66 \%)$ of pleural effusion followed by malignancy (18\%) and parapneumonic Effusion (10\%) [5]. Now a days, diagnosis of pleural effusion by MTB is frequently done by clinical, radiological, histological, and laboratory findings. Latest techniques like liquid culture (Bactac/MGIT), nucleic acid probes, polymerase chain reaction (Gen Xpert) have increased the probability for diagnosing TB earlier. But the gold standard for the diagnosis of Tuberculosis Pleural Effusion (TPE) will remain the detection of Mycobacterium tuberculosis (MTB) in pleural fluid, or pleural biopsy specimens, either by microscopy and/or culture, or the histological demonstration of caseating granulomas in the pleura along with acid fast bacilli. Supportive evidence like demonstration of classical TB granulomas in the pleura and elevated adenosine deaminase (ADA), lactate dehydrogenase (LDH) and alkaline phosphates levels in pleural fluid do help. Baba et al. demonstrated that ADA is a reliable marker of pleural TB in HIV-positive patients, even for those with low CD4 counts, while Chung et al. confirmed that ADA is an accurate marker in renal transplant recipients. On the contrary, raised ADA levels may be observed in a number of conditions potentially leading to a false positive diagnosis of TB which includes rheumatoid effusion, empyema due to other bacteria, mesothelioma, lung cancer, parapneumonic effusion, and haematological malignancies. Pleural fluid analysis will remains an important tool in patients of pleural effusion.

\section{Conclusion}

Though it requires a lot of patience and examination of at least 300 fields under oil immersion microscope to visualize acid fast bacilli in clinical samples but still, $\mathrm{ZN}$ stain is a very strong method to diagnose $\mathrm{TB}$ in resource constraint lab. In addition to that, $\mathrm{ADA}$ values $>70 \mathrm{U} / \mathrm{L}$ are highly supportive of tubercular etiology in pleural fluid even if it is high in many other conditions. Chest X-ray also helps in diagnosis of TPE. Thus to conclude, pleural effusion in India needs to be studied deeply and differently because of more prevalence of tuberculosis in India. The screening of Pleural fluids by $\mathrm{ZN}$ stain in resource constraint settings can provide good results despite low yield.

\section{References}

1. World Health Organization (2012) Global tuberculosis Control. WHO Report 2012, Geneva, Switzerland.

2. World Health Organization (2013) Global Tuberculosis Control. WHO Report 2013 Geneva, Switzerland.

3. Arora VK, Gupta R (2003) Directly observed treatment for tuberculosis. Indian J Pediatr 70: 885-889.

4. TB India (2007) RNTCP status Report. Central TB Division, Directorate General of Health Services, Ministry of Health and Family Welfare, Nirman Bhawan, New Delhi, India.

5. Bhavsar KM, Pujara KM (2015) Pleural effusion: A two year prospective study in Western India. Sch J App Med Sci 3: 2790-2793. 